\title{
Creating Taxonomy for Knowledge Representation of Sustainable Food Systems
}

\author{
Aneta Trajanov \\ Jozef Stefan Institute and Jozef Stefan \\ International Postgraduate School \\ Jamova cesta 39 \\ 1000 Ljubljana, Slovenia \\ aneta.trajanov@ijs.si \\ Tanja Dergan \\ Jozef Stefan Institute \\ Jamova cesta 39 \\ 1000 Ljubljana, Slovenia \\ tanja.dergan@ijs.si \\ Marko Debeljak \\ Jozef Stefan Institute and Jozef Stefan \\ International Postgraduate School \\ Jamova cesta 39 \\ 1000 Ljubljana, Slovenia \\ marko.debeljak@ijs.si
}

\begin{abstract}
Sustainability is becoming a core concept in every area (scientific, social, environmental and economic) of human life. Sustainability acknowledges that human civilization takes resources to sustain our modern way of life and strives towards balancing between our competing needs - our need to continue developing technologically and economically, and the need to protect the environment in which we live. However, sustainability is a very complex concept that incorporates social, environmental and economic aspects and interactions between them and can be described by a number of different sustainability indicators. Therefore, assessing the sustainability of a system is a demanding task and requires gathering and structuring of knowledge from experts, literature surveys and other sources. In this paper, we present the use of taxonomies to represent the complex concept of sustainability of European food systems. Structuring the knowledge on sustainable food systems in Europe is a first step in assessing their level of sustainability. The goal of this study is to use the developed taxonomies as basis for the development of a complex DSS system for assessment of the sustainability of legume food systems across the whole quality chain.
\end{abstract}

Keywords: Language Evolution, Cognitive Evolution, Palaeolithic, Stone Tools, Oldowan, Acheulean, Levallois, Cultural Transmission

Received: 28 August 2018, Revised 31 October 2018, Accepted 10 November 2018

(C) 2019 DLINE. All Rights Reserved

DOI: $10.6025 / \mathrm{jcl} / 2019 / 10 / 1 / 19-26$

International Journal of Computational Linguistics Research Volume 10 Number 1 March 2019 


\section{Introduction}

The world's population is increasing at a speeding rate and with that the production and consumption of food as well. All this comes at an enormous environmental cost. Each year, more than 10 million hectares of arable land are lost to degradation, plant protection products pollute the rivers and aquifers and one third of all greenhouse gas emissions are due to agriculture [4]. Therefore, a shift to more sustainable agri-food systems is needed in order to address these problems. A formal definition of sustainable food systems given by the Food and Agriculture Organization (FAO) states the following: "A sustainable food system is a food system that ensures food security and nutrition for all in such a way that the economic, social and environmental bases to generate food security and nutrition of future generations are not compromised." [2].

Assessment of the sustainability of a food system is not an easy task, as there is not a simple and measurable indicator to assess it. Instead there exists a set of interrelated concepts and indicators that describe the sustainability from different aspects. The sustainability is defined through three main pillars/aspects: economic, social and environmental pillar/aspect (Figure 1) [7].

The economic pillar of sustainability represents the economic functions of the food systems, which should provide prosperity (wealth) to the (farming) community and thus refers to the economic viability of the food system. The social pillar represents several social functions, both at the level of the community, as well as at the level of society (e.g., awareness and legislation protection of the health of people from pollution, or access to basic resources without compromising the quality of life). The environmental pillar represents environmental functions that are connected to the management and conservation of natural resources (water, air, soil, energy and biodiversity) and fluxes within and between these resources [13].

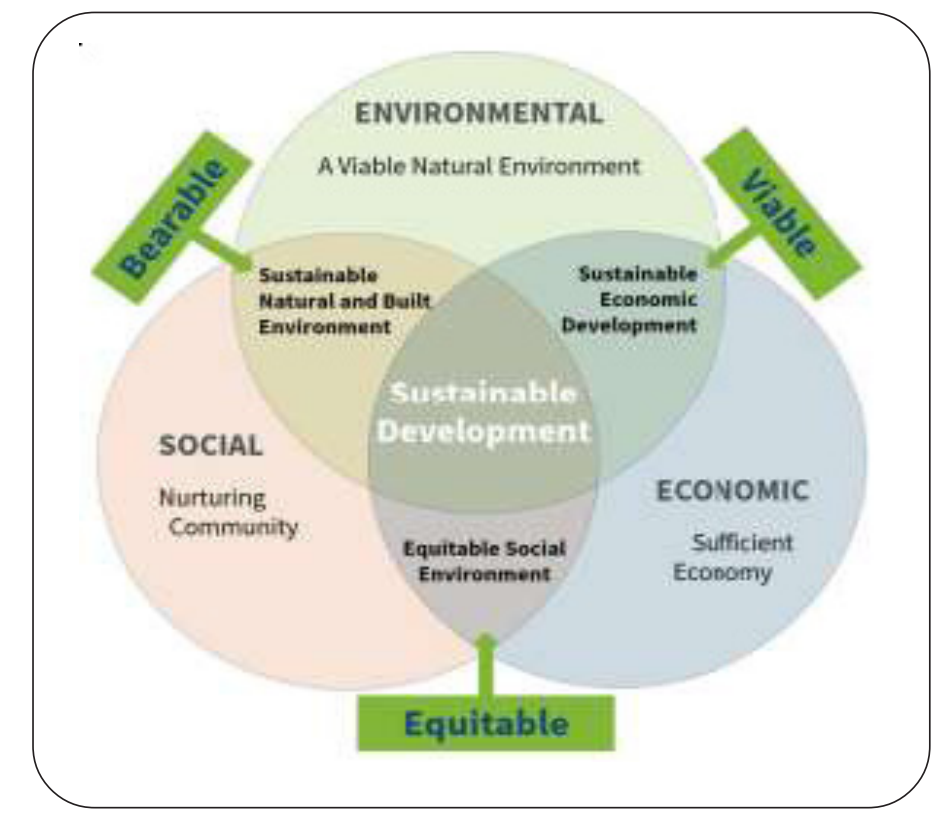

Figure 1. The three pillars of sustainability and their intersections describing partial (bearability, viability, equitability) and overall sustainability

In order to assess the sustainability of a food system, one needs to understand and take into account all these different aspects of sustainability, which is a demanding task. This paper describes the first step towards modelling the transition towards sustainable food systems, which is done within the H2020 project TRUE (TRansition paths towards sustainable legume based systems in Europe) [12]. In order to set the foundations for the development of a Decision Support System (DSS) for sustainability assessment of legume systems, we carried out an extensive literature survey in order to capture as extensive knowledge as possible on sustainable food systems and all the concepts and indicators connected to that. The knowledge and concepts were organized in a hierarchical structure using taxonomies. This kind on knowledge has not been represented in an organized, systematic and formal way so far. Using these taxonomies, we wrote a glossary of terms, which will serve as a knowledge library when constructing the DSS system. 


\section{Materials and Methods}

In order to produce a working protocol for harmonization of data and knowledge to develop the future DSS within the TRUE project, we had to derive definitions of sustainability terms and concepts, and review as much sustainability indicators as possible, which are non-deterministic and ambiguous. For that purpose, we reviewed more than 24 papers and 7 books dealing with different aspects of sustainability of (legume) food systems.

The obtained knowledge from the extensive literature survey was structured using taxonomies. Taxonomies, like ontologies, provide ordered/structured representation of concepts and terms in a form of a hierarchy. They are semantic classification schemes and represent a knowledge map [6]. They are classification schemes, because they group related things together, so that if you search one thing within a category, it is easy to find other related things in that category. They are semantic because they provide a vocabulary to describe the knowledge in them. Finally, if the taxonomy is complete, it should provide an immediate grasp of the overall structure of the knowledge domain it covers.

Many of the taxonomies have hierarchical tree structures. The tree structure is the most intuitive representation, because it provides a visual representation of the relationships between categories and sub-categories, enabling navigation between categories. However, they can be represented in other forms, such as:

- Lists

- Trees

- Hierarchies

- Polyhierarchies

- Matrices

- Facets

- System maps.

The taxonomies presented in this paper are represented in a tree structure and discussed in the Results section.

\section{Taxonomies for Sustainable Food Systems: Results and Discussion}

The taxonomy describing the knowledge on sustainability of food systems in Europe starts by the general sustainability aspect of European food systems (Figure 2). It incorporates sustainability in its general form, sustainability level, sustainability indicators and sustainability assessment.

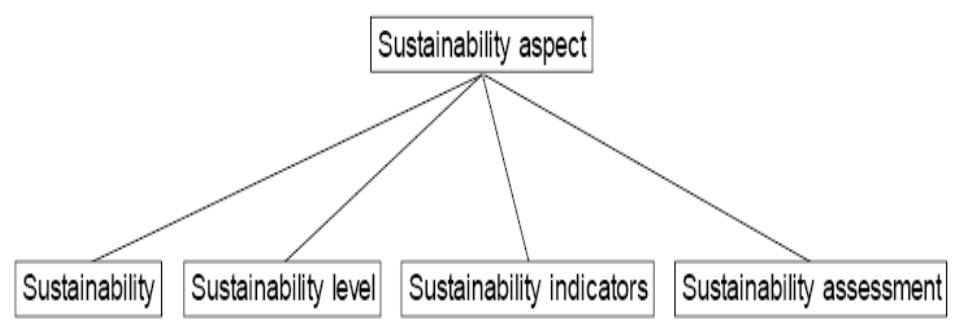

Figure 2. Top level of the taxonomy, decomposing the sustainability aspect into four sublevels: sustainability, sustainability level, sustainability indicators and sustainability assessment

\subsection{Sustainability}

The general sustainability as described in the Introduction section, consists of three sustainability pillars: environmental, social and economic $[5,11]$. True sustainability requires a balance between the environmental, social and economic aspects describing it. Besides these, the intersections between them (bearability, viability and eqitability) are also an important partial aspect of the sustainability as a whole (Figure 3) [5]. 


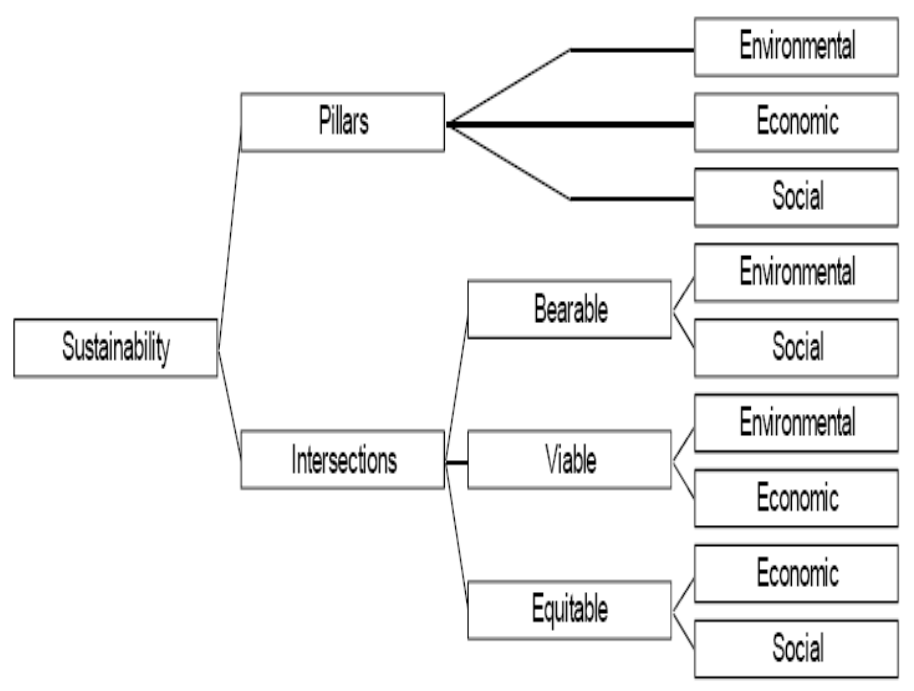

Figure 3. Decomposition of the "Sustainability" part of the taxonomy

Bearability is the intersection between the environmental and social sustainability pillars. It represents a system that is both environmentally and socially sustainable, but lacks an economic sustainability [11]. Viability is the intersection between the environmental and economic sustainability pillars, and equitability is the intersection between the economic and social sustainability pillars.

\subsection{Sustainability Level}

The next part of the taxonomy represents the concepts connected to the sustainability levels, with respect to the different spatial and temporal scales of sustainability. The sustainability levels can be observed and defined through different aspects (Figure 4):

- Normative

- Spatial

- Temporal

- Systems

Normative level refers to the building blocks (aspects) of sustainability (environment, economic, social), which we described earlier, as well as their interactions (equitability, viability, bearability) [3].

The spatial level of sustainability refers to the spatial specifics of sustainability. Sustainability of a food system can be considered/assessed on a local, regional, national or international level [3].

The temporal aspects of sustainability refers to the time horizon of the sustainability assessment.

Finally, the boundary of the (food) system under consideration should be defined, the hierarchy of aggregation levels and their interactions for descriptive, assessment and management purposes in relation to sustainable development, which gives us the system level of sustainability [3].

\subsection{Sustainability Indicators}

Indicators are quantified information, which explain how things are changing over time. The sustainability indicators measure the sustainable development and its progress. They have to reflect the definition of sustainability and be able to connect partial conditions to policies for sustainable development and monitoring its progress [9]. Indicators are used to compare the actual state of the system with reference values for sustainability (sustainability assessment), or with the state of the system in the past and in the future (sustainability monitoring) [13]. The part of the taxonomy addressing the Sustainability indicators is given in Figure 5 . 
Sustainability indicators should satisfy certain criteria, which represent specific objectives relating to a state of the system. The criteria should consider the environmental, economic and social characteristics of the system. They must provide specific conditions for the development of sustainability indicators that will have analytical soundness and will be measurable and suitable for application at different scales (e.g., farm, district, country, etc.).

The actual indicators are variables of any type that can be induced from the sustainability criteria and can provide information about the potential or realized effects of human activities on the sustainability of the food system. These are variables that can be used to assess both the socio-economic and environmental conditions of the food system, to monitor trends and conditions over time, to provide early warning signal of change and a solid basis for decision making processes, consistent with sustainable development principles at all levels $[1,10]$. The indicators can be also used to reduce the complexity of the system description and integrate information about processes, trends or states into a more readily understandable form at local, regional and global levels.

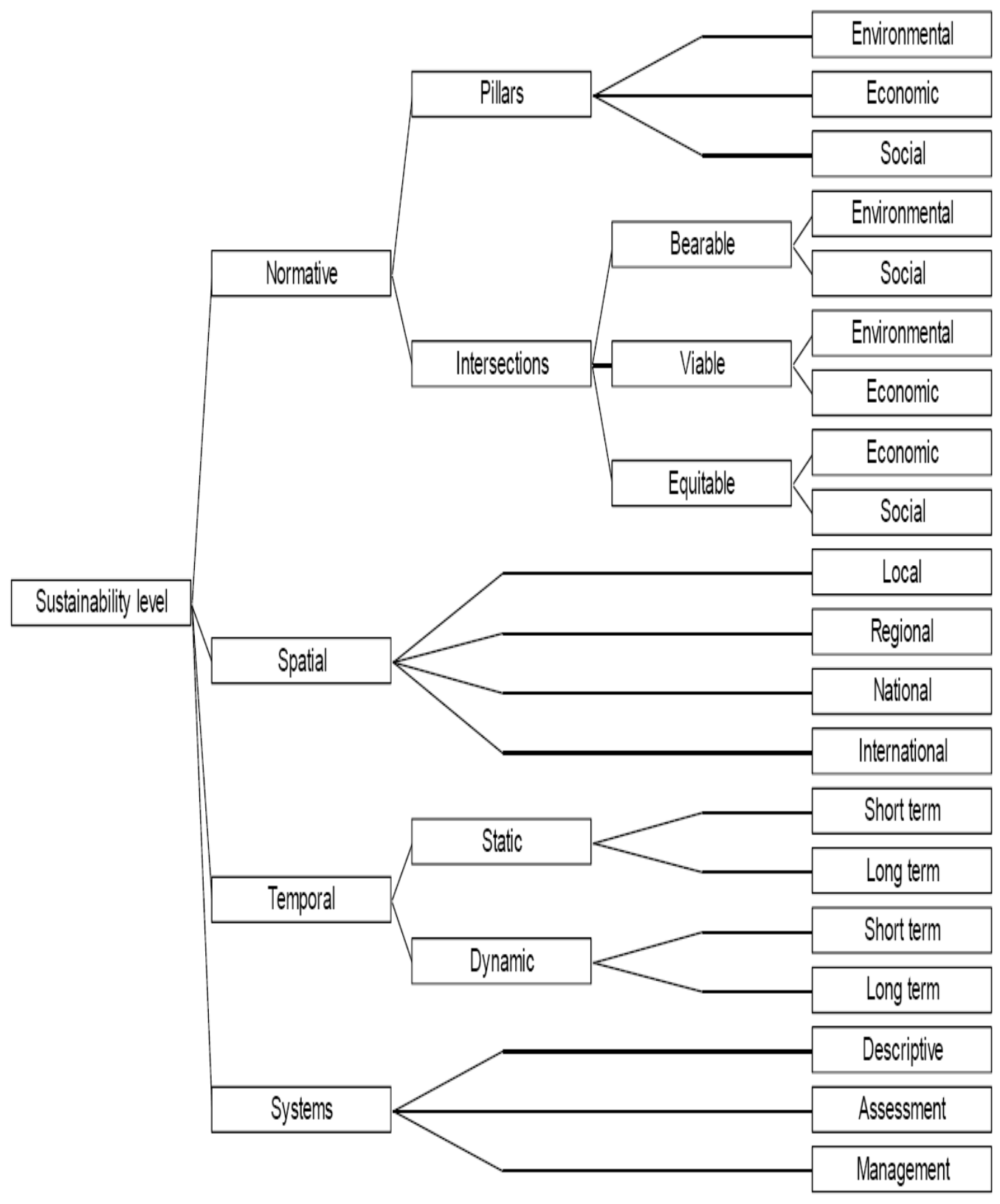

Figure 4. Decomposition of the "Sustainability level" part of the taxonomy 


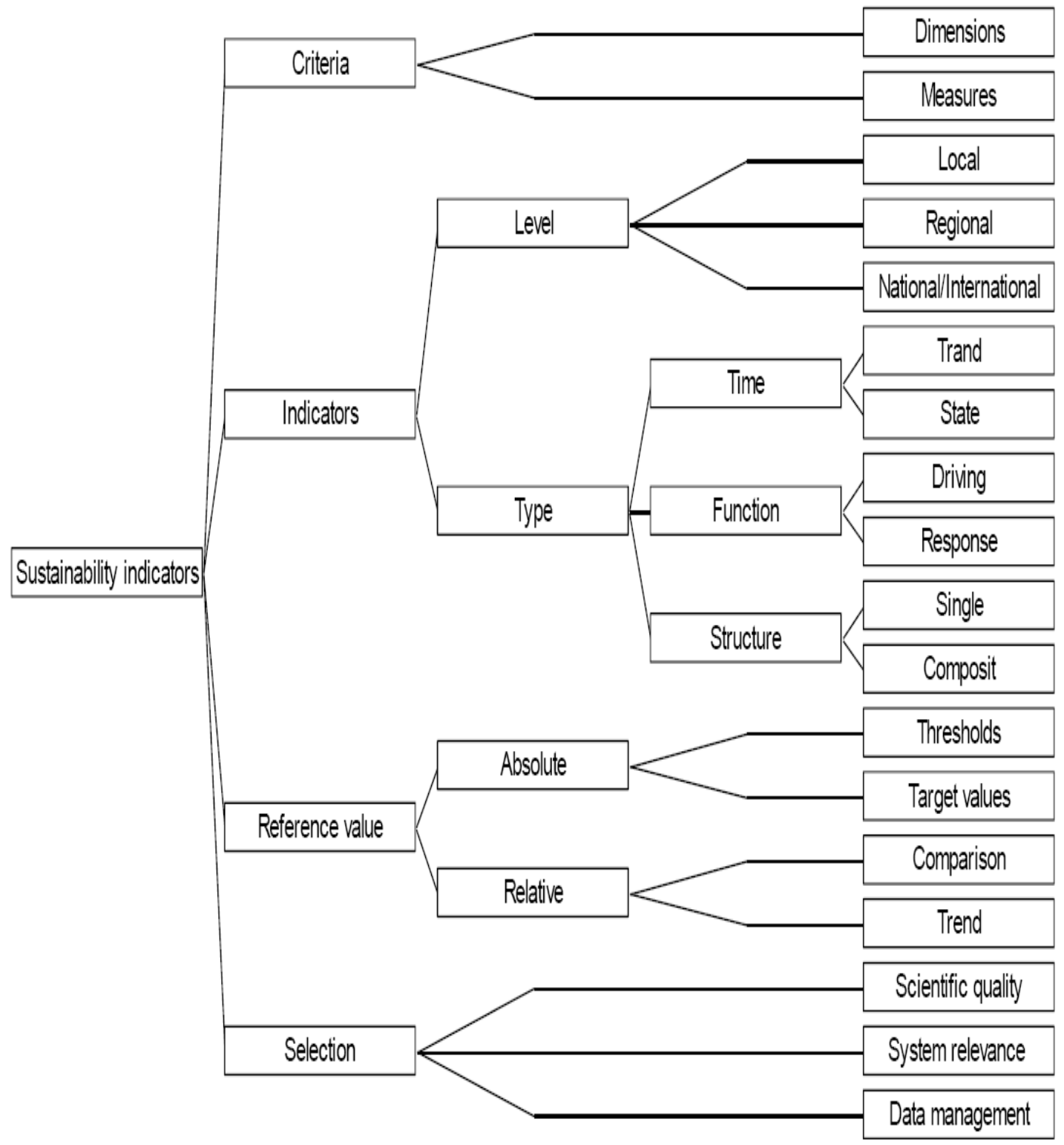

Figure 5. Decomposition of the "Sustainability indicators" part of the taxonomy

The indicators can have different levels $[3,8,10]$ :

- Local - measure the state of the system regarding sustainability

- Regional - compare the system's performance from an economic, social and environmental aspect

- National/international level - inform policy makers about the current state and trends in sector performance and facilitate public participation in sustainability discussions.

- The type of indicators refers to their functional category according to their purpose of use. According to the type, the indicators can describe [1]: 


\section{- Time-Related issues:}

- Trend indicators - describing temporal dynamic aspects of sustainability over time

- State indicators - describing the condition of the assessed system at a certain time point

\section{- Function-Related issues:}

- Driving indicators - measure the changes of the assessed food system due to management practices and other farming inputs

- Response indicators - measure the response of a system to the induced management changes or inputs

\section{- Structure-Related issues:}

- Single indicators - characterizing single parts of the food system

- Composite indicators - aggregate environmental, social and economic indicators into a unique measure describing complex functions and processes of the system.

The reference values of the sustainability indicators refer to the desired level of sustainability for each indicator. They are established on scientific or empirical basis and can be presented as absolute (fixed) values, as threshold values, or as relative reference values according to a selected baseline [13].

Finally, the selection of indicators should be made according to their scientific quality, system relevance and data management principles.

\section{Conclusions}

Structuring and organizing domain knowledge in a structured and formalized way, using taxonomies, is a crucial first step towards understanding complex problems and concepts. It also represents a crucial pre-processing step, which sets the basis for data mining analyses or development of Decision Support Systems.

Within the TRUE project, the taxonomies for knowledge representation of sustainable food systems in Europe were "translated" into a glossary of terms, which will be evaluated by a group of domain experts. In that way, they will validate and confirm the structure of the taxonomy.

The obtained knowledge on sustainability of European food systems, represented using taxonomies will represent the basis for the development of a complex Decision Support System for finding transition pathways towards sustainable legume-based food systems.

\section{Acknowledgments}

This research is supported by the TRUE project, funded by the EU Horizon2020 Research and Innovation Programme, Grant Agreement number 727973.

\section{References}

[1] Dale, V.H., Efroymson, R.A., Kline, K.L., Langholtz, M.H., Leiby, P.N., Oladosu, G.A., Davis, M.R., Downing, M.E., Hilliard, M.R. (2013). Indicators for Assessing Socioeconomic Sustainability of Bioenergy Systems: A Short List of Practical Measures. Ecological Indicators, 26: 87-102.

[2] FAO, (1984). Potential population supporting capacities of lands in the developing world. FAO, (Food and Agriculture Organization of the United Nations), Rome.

[3] Hayati, D., Ranjbar, Z., Karami, E. 2010. Measuring Agricultural Sustainability. In: Biodiversity, Biofuels, Agroforestry and Conservation Agriculture, Eds. Eric Lichtfouse, 5:73-100. Dordrecht: Springer Netherlands.

[4] HLPE, 2014. Food losses and waste in the context of sustainable food systems. A report by the High Level Panel of Experts on 
Food Security and Nutrition of the Committee on World Food Security, Rome 2014.

[5] Kwami, H. I, Che-Ani, A. I., Tawil, N. M., Tahir, M. M., Basri, H. (2014). Approach to Campus Sustainability at Universiti Kebangsaan Malaysia (UKM): A Review. Eds M.A. Othuman Mydin and A.I. Che Ani. E3S Web of Conferences 3. 01011.

[6] Lambe, P. (2007). Organising knowledge: Taxonomies, Knowledge and Organisational Effectiveness. Chandos Publishing, Oxford, England.

[7] Moldan, B., Janouskova, S., Hak, T., (2012). How to understand and measure environmental sustainability: indicators and targets. Ecological Indicators, 17. 4-13.

[8] Muñoz, Lucio. (2016). Linking Sustainable Development Indicators by Means of Present/Absent Sustainability Theory and Indices: The Case of Agenda 21, GDS, IIG, Spain.

[9] Pollesch, N., Dale, V.H. (2015). Applications of Aggregation Theory to Sustainability Assessment. Ecological Economics, 114. $117-27$.

[10] Samuel, V.B., Agamuthu, P., Hashim, M.A. (2013). Indicators for Assessment of Sustainable Production: A Case Study of the Petrochemical Industry in Malaysia. Ecological Indicators, 24. 392-402.

[11] Slocum, S.L. (2015). The Viable, Equitable and Bearable in Tanzania. Tourism Management Perspectives, 16.92-99.

[12] TRUE (TRansition paths towards sUstainable legume based systems in Europe), (2018). H2020 project, https://www.trueproject. eu (11 September 2018).

[13] Van Cauwenbergh, N., Biala, K., Bielders, C., Brouckaert, V., Franchois, L., Cidad, V.G., Hermy, M., Mathijs, E., Muys, B., Reijnders, J., Sauvenier, X., Valckx, J., Vanclooster, M., der Veken, B.V., Wauters, E., Peeters, A. (2007). SAFE - a hierarchical framework for assessing the sustainability of agricultural systems. Agric Ecosyst Environ, 120. 229-2 